\title{
Duas odes horacianas e uma imitação camoniana
}

\author{
Paulo Sérgio de Vasconcellos \\ Instituto de Estudos da Linguagem \\ Universidade Estadual de Campinas
}

\begin{abstract}
RESUMO: As odes I, 4 e IV, 7 de Horácio apresentam elementos comparáveis não apenas do ponto de vista do conteúdo como também do ponto de vista da forma, apesar da diferença de metro e de tom. Neste breve artigo, examinamos essas semelhanças e mostramos como Camões imitou, em uma ode, os dois poemas ao mesmo tempo.
\end{abstract}

PALAVRAS-CHAVE: Odes; Horácio; Camões.

Não escapa a nenhum leitor atento das Odes de Horácio que o poema IV, 7, o célebre Diffugere niues..., trata do mesmo tema da ode I, 4, e de forma muito semelhante. É como se o poeta resolvesse cantar em outro metro' o mesmo tema fundamental, ${ }^{2}$ à semelhança dos poemas dos beijos, os de número 5 e 7 , de Catulo. ${ }^{3}$ Fraenkel (1980, p. 419) afirma que a

I Em ambos os casos, são metros arquilóquios, mas na ode I, 4 se tem um dístico formado de um arquilóquio seguido de um senário iâmbico cataléctico (arquilóquio IV). Na ode IV, 7, tem-se hexâmetro datílico seguido de um ternário datílico cataléctico, sempre segundo a análise estampada na edição das Odes realizada por Villeneuve (1954, p. LXXXI).

2 É óbvio que existem também diferenças marcantes entre um poema e outro; I, 14, por exemplo, esboça brevemente, nos seus dois versos finais, a temática $\pi \alpha 1 \delta \mathrm{i} \eta$, ausente de IV, 7, a menos que se queira vê-la indiretamente evocada na menção da célebre amizade entre Teseu e seu caro Pirítoo, no dístico final. Se essa ilação não for exagerada (não temos conhecimento de utilização desse mito em poemas de feição $\pi \alpha \imath \delta \imath \kappa \eta)$, trata-se de mais um indício da mudança de tom no segundo poema: um paradigma mítico substitui o quadro mais chão da cena simposiática. Além disso, a incitação a desfrutar dos prazeres da vida é reduzida, em IV, 7 a um dístico, que a expressa de forma muito indireta: Cuncta manus auidas fugient heredis, amico/ quae dederis animo ("Fugirá às mãos ávidas do herdeiro tudo/ o que concederes a teu próprio espírito").

3 Tematicamente, a diferença mais marcante entre os dois poemas catulianos parece-nos a seguinte: no poema VII, não se explicita a incitação ao desfrute da vida nem há a tradicional comparação do curso efêmero da vida humana com o ciclo perpétuo, sempre renovado, da natureza. Em resumo, não se enquadra no gênero carpe diem. Como se sabe, o tema dos beijos infindáveis retorna no poema 48 , em contexto homoerótico e temática não enquadrável no gênero carpe diem. 
semelhança não se dá só com relação ao tema básico e à estrutura geral dos poemas, mas "em vários detalhes também". Entretanto, não analisa detidamente a questão, ressaltando 0 aspecto mais sombrio do tema da segunda ode ("It's perhaps only a slight exaggeration to say that in i.4 the thought of death is in the background of the poema but in iv.7 in this centre", p. 420). Para Nisbet e Hubbard (1985, p. 60), IV, 7 "probably draws on similar sources (it is less likely to be a restatement of a theme invented by the poet himself)". A semelhança entre as duas odes mais realçada se torna aos olhos do leitor que as comparar com outra ode horaciana que exalta o início da primavera, a IV, 12: apesar de algumas semelhanças, trata-se de uma composição bastante diversa, na composição dos tópicos e na estrutura geral. As três odes, que compartilham a mesma tópica de base, apresentam, obviamente, pontos em comum na temática e na elocução (por exemplo, o muitas vezes observado iam, presente nas três, assim como no poema 46 de Catulo, que pertence ao mesmo "gểnero"), mas IV, 12 difere das outras duas de maneira muito significativa.

Comecemos apontando as semelhanças temáticas e formais mais evidentes. ${ }^{4}$ Apresentaremos, para comodidade do leitor, o texto das duas odes em foco e a tradução de Elpino Duriense, de que comentaremos alguns aspectos, ao final deste artigo.

O poema I, 4, assim como o IV, 7, é uma típica composição do gểnero "carpe diem"s e tem a construção retórica que Gregson Davis (1991, p. 146 e ss.) identificou: uma descrição da natureza (aqui, a passagem do inverno à primavera) parece motivar uma espécie de insight sobre a precariedade da existência humana, brevíssima e única, ao contrário do perpétuo ciclo da natureza, ${ }^{6}$ e uma conseqüente advertência e incitação a aproveitar a vida.

4 Criticando observações de Heinze, a que não tivemos acesso, sobre a semelhança dos dois poemas horacianos, Quinn (1963) ressalta as diferenças entre um e outro; entretanto, sua análise é, majoritariamente, centrada em minúcias temáticas e nem sempre convincente, como é o caso, por exemplo, de sua observação de que em IV, 4, retrata-se o início da primavera e que em IV, 7 , a primavera já estaria "bem avançada" (p. 16).

5 Um útil sumário da tópica geral desse "gênero", lê-se em Achcar (1994, p. 73). Adotamos o conceito de gênero de Francis Cairns (1972, p. 6): não uma classificação em termos de forma, mas em termos de conteúdo; assim, a análise genérica apontaria, em cada poema, uma elaboração de determinadas unidades de conteúdo necessárias que distinguem um tipo de composição de outro, como também seus elementos secundários, os topoi, ou seja, as "menores divisões do material de cada gênero úteis para fins de análise". A proposta de Cairns traz resultados interessantes para a análise e interpretação, embora não nos leve, necessariamente, a prescindir de classificações tradicionais como as noções de epopéia, tragédia, etc.; não descartamos perspectivas diferentes de análise que não só não se excluem como, na verdade, se completam. $\mathrm{O}$ poema $\mathrm{V}$ de Catulo é do mesmo gênero e apresenta lugares-comuns semelhantes. Pouco percebido, porém, é o contraste entre unidade e multiplicidade que perpassa todos os blocos temáticos em que é possível dividi-lo. Primeiramente, há a forte antítese, realçada pela proximidade, entre omnes (rumores) e unius (assis); depois a multiplicação do sol (soles) contraposta à breve lux da existência humana (note-se semel, que significa, isoladamente, "uma só vez"); a multiplicação sôfrega dos beijos em mille e centum infindáveis; por fim, o malus que pode pôr olho gordo numa soma tão grande de beijos (tantum...basiorum). Ao contrário do que ocorre nas odes horacianas em questão, a representação da natureza em seu aspecto cíclico (occidere et redire) é sumária, reduzindo-se a um único verso. 
Esse esquema dá conta das linhas gerais da tópica nele desenvolvida, que aparece, porém, configurada de forma variada e com diferente ordem de apresentação dos elementos temáticos secundários. No primeiro poema, a descrição da paisagem vai do primeiro verso ao quarto, ao qual se segue uma delicada pintura de personagens míticos (Vênus que, ao lado das ninfas e das Graças, conduz coros sob a alta lua). No segundo, também vai do primeiro verso ao quarto, e a menção à Graça e às Ninfas (Vênus desaparece) ocupa dois versos.

Numa análise temática sumária e geral, vê-se que a ode I, 4 pode ser dividida em blocos temáticos de quatro versos, com exceção do último, que se desenrola por oito versos:

Cena: fim do inverno e começo da primavera (v. 1-4)

Cena: dança de Vênus, Ninfas e Graças; atividade de Vulcano (v. 5-8)

Comportamento adequado ao homem (v. 9-12)

Iminência da morte e incitamento a Séxtio; "carpe diem" (v. 13-20)

Em IV, 7, há pelo menos três blocos temáticos de quatro versos, oração cujo início deve ser emparelhado com o início dos demais parágrafos.

Cena: fim do inverno e começo da primavera (v. 1-4)

Ciclo das estações do ano (v. 9-12)

Contraste entre natureza e efemeridade da vida humana (v. 13-16)

Os demais blocos se agrupam em dois versos: v.5-6, 7-8 e 17-18, 19-20, que, em sequência, como se vê, poderiam ser agrupados também em grupos de quatro, mas preferimos evitar qualquer possibilidade de forçar a interpretação. ${ }^{7}$ Quanto ao grupo de versos que resta, é justamente o bloco temático final, que adverte o interlocutor sobre seu destino irrevogável depois de morto, e tem... oito versos, como no caso da primeira ode! Ambos os poemas têm uma estrutura indiscutivelmente próxima sob esse aspecto: uma progressão em unidades temáticas comparáveis que termina por uma unidade de extensão maior; são grupos quase sempre de quatro versos com uma sequiência final de oito.

Note-se, nas duas odes, o andamento sintático comparável; um verbo inicia o verso e o sujeito é posposto e expresso imediatamente:

Soluitur acris hiems

Diffugere niues

No primeiro poema, a descrição do comportamento do gado e do lavrador em face da primavera que se inicia é expresso num quiasmo:

7 Estamos cientes dos problemas teóricos desse tipo de análise formal, mas acreditamos que, seja como for, há análises mais convincentes e menos convincentes. Para uma discussão teórica das relações, num texto, entre o todo e suas partes, veja-se Sharrock (2000, p. 15-16), de cujas páginas destacamos: "There is no escape from absolutizing of the 'part-ing' involved in reading. However large or small you make the parts, a decision must be made about where to bite, and that decision conditions and is conditioned by the act of reading. [...] To say it is a "part" is an act of interpretation." 
ac neque iam stabulis gaudet pecus//aut arator igni (//: cesura)
B
A
A B (A: sujeito;
B: ablativo instrumental)

A segunda ode, ao descrever as mudanças na natureza, apresenta também um quiasmo:

redeunt gramina campis/ arboribusque comae ${ }^{8}$
A
B
B
A (A: sujeito; B: dativo)

A presença dessa figura sintática no mesmo bloco temático comparável em uma e outra ode já é interessante. Horácio emprega recurso semelhante com palavras diferentes, em métrica diversa. No plano semântico, há um outro paralelo curioso nesses primeiros versos. Com sua técnica hábil de sugerir sutilmente sentidos a partir do uso inesperado de palavras corriqueiras, numa espécie de "extra" de espessor semântico conferido a uma expressão aparentemente singela, o poeta, antes mesmo de traçar o paralelo entre a natureza e a vida humana, como que anuncia seu tema principal, ao humanizar com um pequeno detalhe descritivo a natureza, representando os efeitos do inverno sobre os prados como uma espécie de "velhice", nesse caso, apenas provisória. De fato, no segundo verso da ode I, 4 representam-se os prados embranquecidos por canis...pruinis ("alvas geadas"). Ora, o leitor será incitado a comparar o ciclo das estações ao curso delimitado da vida humana; nesse processo de metaforização alegórica se contrastará o inverno com a velhice, um antigo topos. Em leitura retrospectiva, ${ }^{9}$ o leitor terá mais clarividência para perceber que já de início o poema introduziu uma humanização da paisagem, aplicando a geadas um adjetivo que lembraria a qualquer falante de latim os cabelos brancos da velhice (cf. "cãs"). ${ }^{10}$ No segundo poema, como que de novo empregando recurso semelhante, Horácio faz o mesmo de forma diversa. Aqui, a transição para a primavera é descrita pelo retornar às árvores de suas "comas" (comae), uma palavra ambígua: no sentido mais banal, na interpretação superficial, primeira, do poema, "fronde", "folhagem", mas, especialmente em leitura retrospectiva, "cabelos"," que é, como se sabe, o sentido original da

8 Elpino Duriense, pseudônimo de Antônio Ribeiro dos Santos (1745-1818), tradutor português das Odes, é fiel a esse aspecto da sintaxe expressiva do poema: "torna aos campos/A relva, e a grenha às árvores". Sobre o tradutor, consulte-se Achcar (1994, p. 113).

9 "In any language, sometimes something later in a sentence will cause the reader to change her perception of something earlier, to reread it even without moving her eyes. Indeed, we read literary texts in the expectation that this reappraisal will happen" (Sharrock, 2000, p. 36). Este é um dos aspectos da não-linearidade de toda leitura de um texto literário, mas é óbvio que a leitura crítica se detém particularmente nesse tipo de operação interpretativa.

10 "Canus, - $a$, -um: blanc, et spécialement 'aux cheveux blancs, chenu'. Pluriel substantivé cani "cheveux blancs"” (DELL, p. 168).

11 Elpino Duriense conservou, em sua tradução da ode, a linguagem figurada com o emprego do substantivo "grenha", que pode ter, como se verifica no Houaiss, duplo sentido: "cabelo emaranhado" e "ramagem enredada", sendo este segundo sentido o figurado. Em tradição literal, 
palavra grega que o latim adotou (mas já na Odisséia empregada com o sentido de "fronde" das árvores).$^{12} \mathrm{~A}$ sequiência do poema leva o leitor que faz o caminho de volta, relendo, a semantizar canis e comae de uma forma que seria certamente mais difícil realizar na leitura única e linear. ${ }^{13}$ Semelhantemente, na ode IV, 7, o verbo decidere, empregado para referir a passagem para o reino dos mortos (nos ubi decidimus/ quo pater Aeneas... v. 1415) faz pensar: como a natureza e a vida humana foram comparadas e contrastadas, parece reverberar, no verbo, seu sentido primeiro e seu emprego para referir a queda dos frutos e folhas das árvores (sobre a aplicação aos frutos, ver Cícero, Cato Maior XIX, 71). De forma sutil, a morte do ser humano é comparada à queda de um fruto e essa idéia é realçada pelo enjambement. No poema $\mathrm{V}$ de Catulo o processo de metaforização é mais evidente, porque aparece sob a forma de uma comparação explícita entre o pôr-do-sol, fim provisório, e o findar definitivo da vida humana com a morte: Soles occidere et redire possunt;/ Nobis cum semel occidit breuis lux.

Nas duas odes horacianas, portanto, a humanização da natureza faz referência sutil aos cabelos humanos. É um exemplo da rede fina de sentidos que o poema horaciono tece e que a cada nova leitura vai-se tornando mais visível, pois uma releitura ativa o significado metafórico que estava latente, de forma sutil, num momento do texto em que a leitura primeira e linear facilmente o escamotearia. Em si, não há estranhamento gritante nas expressões canis pruinis e arboribus comae; mas o universo semiótico do texto em sua totalidade faz o leitor reconsiderar essa sua impressão e extrair certos efeitos de sentido de forma mais evidente: uma interpenetração direta entre a natureza e a vida humana, os dois universos que são contrastados ao longo das composições.

Outro dado curioso diz respeito à sintaxe expressiva. No final da primeira ode, há um quiasmo extenso:

et domus exilis Plutonia, quo simul mearis A-B nec regna uini sortiere talis $\mathrm{C}$

José Agostinho de Macedo (século XVIII) traz "coma", que pode significar "cabelo crescido, grande" e "copa de árvore frondosa", sempre segundo o Houaiss. Sobre este último tradutor, veja-se Achcar, p. 109 e ss.

$\left.{ }_{12} \kappa \delta \mu \eta \nu . . . \dot{\varepsilon} \lambda \alpha i \eta\right\rceil(23,195)$. Há exemplo em Catulo IV: comata silua (v. 11), loquente coma (v. 12).

${ }^{13}$ O mesmo se pode dizer do interitura aplicado a aestas no verso 10 da segunda ode: o verão há de morrer (interitura), assim como morrem os seres humanos. Aqui, poderíamos lembrar a observação arguta de Nietzsche sobre as odes de Horácio: "Este mosaico de palavras no qual cada palavra expande sua a sua força como som, como posição, como conceito, à direita e à esquerda, "este minimum na extensão e no número dos signos e este maximum. assim obtido, na energia dos signos" (Crepúsculo dos Ídolos; traduzimos a passagem de edição italiana indicada nas referências bibliográficas. A tradução italiana original é de Mirella Ulivieri). O procedimento metafórico tem a sutileza que não se vê em outra ode, a IV, 13, do próprio Horácio, que nela emprega a expressão capitis niues, evidenciando a comparação, em metáfora repreendida por Quintiliano (Inst. Or. VIII, 6, 17), que a condena como dura e a longinqua similitudine ducta. 


\section{nec tenerum Lycidam mirabere, quo calet iuuentus C-B nunc omnis et mox uirgines tepebunt. ${ }^{14} \mathrm{~A}$}

No segundo poema, o quiasmo é menos vistoso: ao composto de objeto acusativo mais sujeito nominativo se sucedem sujeitos mais objetos:
Non, Torquate, genus, non te facundia, non $t e$ restituet pietas,
B: objeto acusativo
A: sujeito nominativo
infernis neque enim tenebris Diana pudicum liberat Hippolytum,
nec Lethaea ualet Theseus abrumpere caro uincula Pirithoo.
A: sujeito nominativo
B: objeto acusativo
A: sujeito nominativo
B: objeto acusativo

Não precisamos nos deter na análise para concluir que no segundo poema o quiasmo é muito mais tênue, mas que haja aí a possibilidade de encontrar a mesma figura sintática que encerra o primeiro é digno de nota.

Ainda no âmbito sintático, pode-se contrastar as duas odes pelo emprego da disjunção. Nos dois poemas há constantes disjunções entre adjetivo e substantivo por ele modificado, mas o processo é mais refinado na segunda: aqui, um adjetivo no primeiro verso modifica um substantivo no segundo, numa espécie de entrelaçamento sintático no dístico difícil de manter numa tradução para o português.

Na primeira ode, temos as seguintes disjunções:

$$
\begin{aligned}
& \text { siccas (imediatamente antes de cesura) carinas - verso } 2 \\
& \text { canis (imediatamente antes de cesura) pruinis - verso } 4
\end{aligned}
$$

14 É curioso observar que o poema $V$ de Catulo, que é o grande predecessor latino de Horácio no gênero do "carpe diem", pelo menos pelo que se pode afirmar a partir do que restou da poesia antiga, apresenta também um expressivo quiasmo nos seus versos finais, cujo sentido procuramos analisar em outra parte (ver bibliografia): Dein, cum milia multa fecerimus (A: adverbial temporal) /Conturbabimus illa, ne sciamus (B: adverbial final), /Aut ne quis malus inuidere possit, (B)/Cum tantum sciat esse basiorum (A). A ode IV, 7 apresenta ecos verbais do poema V: Cum semel occideris (no poema V, 5: Cum semel occidit). Ao se aproximarem os textos, vemos que se em Catulo aparece um plural soles, em Horácio aparece o plural lunae, o que faz pensar na interpretação do verso da ode em questão, muito discutida. Talvez se nos indague: mas é lícito, em condições "normais" de leitura, isto é, abstraindo o trabalho do pesquisador de fontes e ecos verbais, recorrer a um outro texto para explicar o sentido de um texto poético? É uma questão complexa, que só podemos aflorar aqui. Em suma, a nosso ver, o caráter da "arte alusiva", que incita ao confronto de textos, ativa possibilidades interpretativas vedadas à leitura não alusiva: caminhos que se bifurcam e se interpenetram quebrando a sucessão linear da construção de sentido da leitura "superficial" do ponto de vista intertextual. Dá-se o mesmo na leitura "intratextual" que volta em retrospecto ao texto para tecer associações de sentido que uma leitura linear e "reta" escamoteia. Assim, ao leitor fica confiada, virtualmente, a tarefa criativa de (re)construir o mesmo texto de formas variadas, usufruindo dos efeitos de leitura que essa operação interpretativa lhe facultará. 


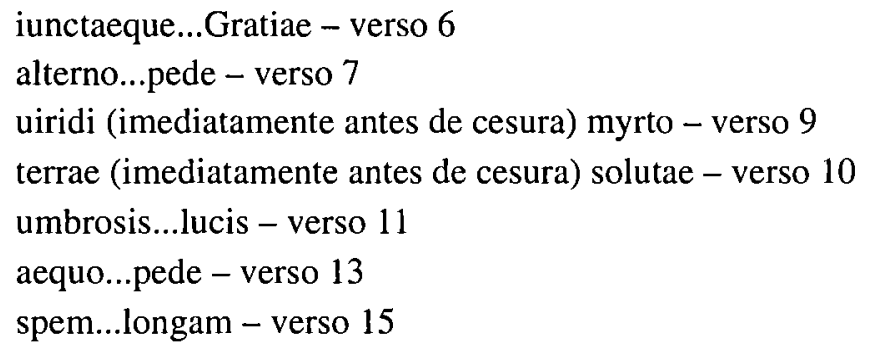

Há apenas um tipo de disjunção que tem o esquema que abundará na segunda ode:

alterno terram quatiunt pede, dum grauis Cyclopum

Volcanus ardens uisit officinas. (v. 7-8)

No passo acima, o sintagma adjetivo-substantivo é dividido entre dois versos. Esse tipo de esquema aparece nos seguintes passos da segunda ode:

mutat terra uices et decrescentia ripas

flumina praetereunt (v. 3-4)

Inmortalia ne speres, monet annus et almum quae rapit hora diem. (v. 7-8)

Quis scit an adiciant hodiernae crastina summae tempora di superi? (v. 17-18)

Cuncta manus auidas fugient heredis amico quae dederis animo. (v. 19-20)

Cum semel occideris et de te splendida Minos fecerit arbitria (v. 21-22)

infernis neque enim tenebris Diana pudicum liberat Hyppolytum, nec Lethaea (a) ualet Theseus abrumpere caro (b) uincula (A) Pirithoo (B).

É notável a presença desse tipo de disjunção. Numa passagem, passa-se algo semelhante, mas desta vez o sintagma é composto de substantivo mais adjetivo:

Gratia cum Nymphis geminisque sororibus audet ducere $n u d a$ choros. (v. 5-6)

Temos, também, quatro exemplos de disjunção operada num mesmo verso; dois deles vêm em um verso que apresenta esquema sintático refinado (A: substantivo; B: adjetivo): 
Damna (A) tamen celeres (b) reparant caelestia (a) lunae (B) (verso 13) ${ }^{15}$

Por fim, os dois outros exemplos de disjunção em mesmo verso:

Quis scit an adiciant hodiernae cratina summae

infernis neque enim tenebris

Notemos, agora, léxico semelhante que aparece nos dois textos:

iunctae Nymphis Gratiae / Gratia cum Nymphis

ducere...choros / choros ducit

quo (...) quo.../ quo...quo

summa / summae

et $\operatorname{mox} /$ et $\operatorname{mox}$

Retomemos, então, os versos 23 e 24 e observemos um curioso jogo fônico:

Non Torquate, genus, non te facundia, non te restituet pietas

No primeiro verso a forma de segunda pessoa tem seus sons fortemente reiterados; no seguinte, os sons dessa forma aparecem duas vezes invertidos (notemos também a aliteração em /t/ que, de alguma forma, chama a atenção para o fenômeno). De que maneira interpretá-lo? Como leitor de poesia, com a liberdade relativamente delimitada pelas virtualidades que o texto ativa, podemos propor que o processo mimetiza a impossibilidade mesma de escapar do mundo infernal. Notemos, do primeiro ao segundo verso a impressão de "soltura" cada vez menor dos sons que ecoam a segunda pessoa: primeiramente, comparece no final de um nome próprio (Torquate), depois como objeto inserido entre uma negação e um sujeito nominativo (non te facundia), depois em fim de verso (non te), aparentemente mais independente, mas encadeado em enjambement com o verso seguinte, que traz o verbo (restituet), de que é complemento; depois disso, o som ecoa "preso" a formas que o reproduzem de maneira invertida (restituet pietas)... Maneira hábil e sutil de reproduzir no enunciado as malhas infernais que impedirão Torquarto de voltar à vida uma vez descido às profundezas do Hades. Chegados a este ponto, vamos de novo à primeira ode e encontramos um Iam te premet nox fabulaeque Manes (v. 16) em que te premet ("sobre ti pesará")

15 A nosso ver, essas figuras sintáticas contribuem para a impressão geral de que a segunda ode é mais refinada, mais alexandrina, ou, para atenuar o aspecto de valoração positiva que esses termos terão, sem querermos, mais artificiosa. E se na primeira ode se menciona a casa de Plutão como morada última do homem, na segunda há, além da referência a Minos, o recurso ao paralelo mitológico, com a menção a Diana/Hipólito e Teseu/Pirítoo; um traço de erudição bastante distintivo. (Note-se também que o Fauonius da primeira "versão" aparece na forma de seu equivalente grego Zephyri, na segunda). 
parece trazer em germe o jogo que se desenvolverá e se explicitará (relativamente) na segunda ode. ${ }^{16}$

Um leitor atento de poesia, um poeta, e dos maiores, demonstra com um ato criativo ter observado com atenção a semelhança entre os dois poemas horacianos: Camões "imitou" as duas odes e as fundiu num só poema, acrescentando, como era de esperar, elementos novos. Transcrevemos o texto abaixo, apontando com as letras A e B o material tomado das odes I, 4 e IV, 7, respectivamente (indica-se pelo itálico as retomadas textuais mais evidentes):

Fogem as neves frias

dos altos montes, e já reverdecem

as árvores sombrias;

as verdes ervas crescem

e o prado ameno de mil cores tecem.

Zéfiro brando aspira;

suas setas Amor afia agora;

Progne triste suspira,

e Filomela chora;

o céu da fresca terra se namora.

Vai Vênus Citle]réia

com os coros das Ninfas rodeadas:

a linda [Pasitéia],

despida e delicada,

com as duas irmãs acompanhada.

16 É interessante ressaltar que, se não tivéssemos em mente o jogo fônico da segunda ode, não teríamos prestado atenção ao jogo do primeiro, que é mais sutil e destinado a passar despercebido numa leitura "isolada". Essa constatação certamente revela como é complexo o processo de leitura e interpretação, o modo como o leitor constrói e reconstrói a teia de significados ativados pelos textos.

17 Os equivalentes latinos retomados: Diffugere niues (Fogem as neves); redeunt iam gramina (já reverdecem; ervas) campis (prado) arboribusque (árvores) comae. Note-se como Camões acrescenta epítetos às expressões horacianas: "neves frias", "árvores sombrias", que se deve entender no sentido de "que dão sombra", por isso, copadas (desta forma, retomando indiretamente comae), "verdes ervas", "prado ameno".

"Zéfiro brando" retoma mitescunt Zephyris ("[os frios] se abrandam com os Zéfiros"); novamente, vê-se a preferência camoniana pelo epíteto.

Cytherea... Venus. cum Nymphis...choros.

21 Nuda.

22 Gratia [Pasitéia: Camões menciona o nome tradicional de uma das Graças]... geminibusque sororibus.

Dum...Cyclopum/Volcanus ardens urit officinas. 


\section{Do[s] Ciclope[s] Vulcano está queimando, ${ }^{24}$}

vão colhendo boninas

as ninfas, e cantando;

a terra com o ligeiro pé tocando.

Desce do duro monte

Diana, já cansada da espessura, buscando a clara fonte, onde por sorte dura Perdeu Acteon a natural figura.

Assim se vai passando

a verde primavera, e seco estio;

trás el[e] vem chegando, depois, o inverno frio, que também passará por certo fio.

Ir-se-á embranquecendo com a frígida neve o seco monte;

e Júpiter chovendo turbará a clara fonte; temerá o marinheiro o [Orionte].

Porque, enfim, tudo passa, não sabe o tempo ter firmeza em nada; e nossa vida escassa foge tão apressada que, quando se começa, é acabada.

Que foram dos troianos

Heitor temido, Enéias piedoso? ${ }^{27}$

Consumiram-te os anos, ó Cresso tão famoso, sem te valer teu ouro precioso.

Todo o contentamento

crias que estava em ter tesouro ufano, ó falso pensamento,

24 Obviamente, Camões seguiu a lição urit, não uisit, adotada pela edição da Belles Lettres que seguimos.

25 Alterno terram quatiunt pede: "pé alternado" se torna "pé ligeiro" em Camões.

26 Imita-se aqui, de forma mais livre, o ciclo das estações do ano descrito em II, 7, v. 9-12. Se na ode horacina, os rigores do frio são simbolizados pela aliteração em /r/: bruma recurrit iners, em Camões o eco do agudo /i/ na rima em -io parece-nos apresentar algo de semelhante.

27 Obviamente, Camões leu texto que trazia lição pius, ao invés de pater. A primeira parece-nos mais adequada ao contexto: apesar de sua pietas, nem mesmo Enéias pôde escapar aos grilhões da morte. 
que, à custa de teu dano, do do[u] to Sólon creste o desengano.

$O$ bem que aqui se alcança não dura por possante, nem por forte; que a bem-aventurança durável, de outra sorte se há de alcançar [n]a vida para a morte

Porque, enfim, nada basta contra o terríbil fim da noite eterna nem pode a deusa casta tornar à luz superna Hipólito da escura noite averna.

Nem Teseu esforçado com manha, nem com força rigorosa livrar pode o ousado Piritoo da espantosa prisão letéia, escura e tenebrosa. ${ }^{30}$

Poderíamos dizer que Camões imitou, no conjunto, a ode IV, 7, acrescentando-lhe, porém, elementos da ode I, 4 (além de outros hipotextos que aqui não nos interessam), num processo de contaminatio que não é incomum na "imitação" praticada pelos antigos romanos. Mais curioso: sua ode se deixa dividir em grupos de cinco versos, mas ao final se distingue uma unidade de dez versos. Leitor finíssimo, não é de surpreender que Camões tenha percebido, pelo que se vê de sua "imitação", esse aspecto da estrutura poética presente nas duas odes horacianas que reelaborou e fundiu: unidades temáticas terminadas por uma unidade final que tem o dobro de versos das anteriores.

Abaixo, apresentamos o texto latino das duas odes e a tradução de Elpino Duriense:

$$
\text { I, } 4
$$

Soluitur acris hiems grata uice ueris et Fauoni trahuntque siccas machinae carinas, ac neque iam stabulis gaudet pecus aut arator igni nec prata canis albicant pruinis.

28 infernis neque enim tenebris Diana pudicum / liberat Hippolytum.

29 nec Lethaea ualet Theseus abrumpere.../uincula Pirithoo. Note-se que o adjetivo aplicado ao amigo de Teseu em Horácio, caro, tornou-se "ousado" em Camões. Observe-se também que dois epítetos são associados a "prisão", "tenebrosa" e "escura", com redundância semântica.

30 Modernizamos a ortografia do texto estabelecido por Leodegário A. de Azevedo Filho apud SPAGGIARI, Barbara et alii. O Renascimento Italiano e a Poesia Lírica de Camões. Rio de Janeiro: EDUFF-Tempo Brasileiro, 1992, p. 47-48. 
Iam Cytherea choros ducit Venus imminente luna iunctaeque Nymphis Gratiae decentes

alterno terram quatiunt pede, dum grauis Cyclopum Volcanus ardens uisit officinas.

Nunc decet aut uiridi nitidum caput impedire myrto aut flore, terrae quem ferunt solutae;

nunc et in umbrosis Fauno decet immolare lucis, seu poscat agna siue malit haedo.

Pallida Mors aequo pulsat pede pauperum tabernas regumque turris. $O$ beate Sesti,

uitae summa breuis spem nos uetat inchoare longam. Iam te premet nox fabulaeque Manes

et domus exilis Plutonia, quo simul mearis, nec regna uini sortiere talis

nec tenerum Lycidan mirabere, quo calet iuuentus nunc omnis et mox uirgines tepebunt.

\section{7}

Diffugere niues, redeunt iam gramina campis arboribusque comae;

mutat terra uices et decrescentia ripas flumina praetereunt;

Gratia cum Nymphis geminisque sororibus audet ducere nuda choros.

Inmortalia ne speres, monet annus et almum quae rapit hora diem.

Frigora mitescunt Zephyris, uer proterit aestas, interitura simul

pomifer autumnus fruges effuderit, et mox bruma recurrit iners.

Damna tamen celeres reparant caelestia lunae: nos ubi decidimus quo pater Aeneas, quo diues Tullus et Ancus, puluis et umbra sumus.

Quis scit an adiciant hodiernae crastina summae tempora di superi?

Cuncta manus auidas fugient heredis, amico quae dederis animo.

Cum semel occideris et de te splendida Minos fecerit arbitria, 
non, Torquate, genus, non te facundia, non te restituet pietas;

infernis neque enim tenebris Diana pudicum liberat Hippolytum,

nec Lethaea ualet Theseus abrumpere caro uincula Pirithoo.

\section{I, 4}

Desfaz-se o agro inverno com agradável Sezão da primavera e de favônio: $\mathrm{E}$ as máquinas as secas naus arrastram.

E nem dos currais gostam

O gado já, ou lavrador do fogo;

Nem os prados com branco gelo alvejam Já Vênus citérea os coros rege

Sob a iminente lua:

Junta com as ninfas as airosas graças Com alternado pé a terra batem; Ao passo que Vulcano dos Ciclopes

As duras oficinas

Ardente abrasa. Ora com verde mirto Cumpre cingir a nítida cabeça, Ou com a flor, que baldias terras criam.

Ora no luco umbroso

Cumpre sacrificar a fauno, ou peça Cordeira, ou um cabrito mais the apraza. Com pé igual pálida morte pulsa

Dos pobres os alvergues,

E os palácios dos reis, ó feliz Séstio, Da vida a breve soma nos defende Entrar em longas esperanças. Logo

A noite, e os fabulosos

Manes, e a sutil plutônia estância

Hão de oprimir-te: aonde assim que entrares, 
tu nunca mais sortearás aos dados

O império do vinho. ${ }^{31}$

IV, $7^{32}$

Já fugiram as neves, torna aos campos

A relva, e a grenha às árbores:

Muda a terra a estação, no leito correm

Os rios já minguados:

Com as ninfas e irmãs gêmeas ousa a graça

Guiar despida os coros,

O ano, e a hora, que o almo dia rouba,

Te avisam, que não esperes

Coisa imortal: os frios se amaciam

Com os zéfiros, o estio

A primavera calca, precedeiro,

Quando espalhar os frutos

O pomífero outono: eis volta o inverno

Inerte; mas as luas

Presto reparam os celestes danos.

Nós mal caímos, onde

Enéias pio, rico Tulo e Anco,

Já somos pó e sombra.

Quem sabe, os tempos de amanhã se ajuntam

Aos de hoje os altos deuses?

Foge às ávidas mãos do herdeiro, quanto

Dás a teu gênio amigo.

Como uma vez morreres, e a esplendente

Sentença te der Minos,

Nem linhagem, Torquato, nem facúndia,

Nem virtude te livra;

Que nem das trevas infernais Diana

Casto Hipólito salva,

Nem as prisões do Letes Teseu pode

Quebrar ao seu Piritôo.

31 A edição que consultamos não traz o que seria a tradução dos dois últimos versos, em pudica censura da alusão ao erotismo pederástico.

32 IV, 6, na edição consultada. 


\section{Referências Bibliográficas}

ACHCAR, Francisco. Lirica e lugar-comum. Alguns temas de Horácio e sua presença em português. São Paulo: Edusp, 1994.

CATULO. O Cancioneiro de Lésbia. Tradução, introdução e notas de Paulo Sérgio de Vasconcellos. São Paulo: Hucitec, 1990.

CICERONE. Catone Maggiore. Commento e note di Felice Ramorino. Torino: Loescher, 1968.

DAVIS, Gregson. Polyhymnia. The rethoric of Horatian lyric discourse. Berkeley: University of California Press, 1991.

HOUAISS, Instituto Antonio. Dicionário Houaiss da língua portuguesa. Rio de Janeiro, Objetiva, 2001.

HORÁCIO. Obras completas. Em traduções de Elpino Duriense, José Agostinho de Macedo, Antônio Luiz de Seabra e Francisco Antônio Picot. São Paulo: Edições Cultura, 1941.

NIETSZCHE. Opere 1822/1895. Trad. de Mirella Ulivieri. Roma: Newton, 1993.

NISBET, R. G.M.; HUBBARD, Margaret. A Commentary on Horace odes. Book 1. Oxford: Clarendon Press, 1985.

QUINN, Kenneth. Latin Explorations. Critical studies in Roman literature. London: Routledge and Kegan Paul, 1963.

SHARROCK, Alison; MORALES, Helen. Intratextuality. Greek and Roman textual relations. Oxford: Oxford University Press, 2000.

SPAGGIARI, Barbara et alii. O Renascimento italiano e a poesia lírica de Camões. Rio de Janeiro: EDUFF-Tempo Brasileiro, 1992.

VILLENEUVE, F. Horace. Odes et épodes. Texte établi et traduit par F. Villeneuve. Paris: "Les Belles Lettres", 1954.

VASCONCELLOS, Paulo Sérgio de. Deux odes horaciennes et une imitation camonienne. Classica, São Paulo, v. 15/16, n. 15/16, p. 233-247, 2002/2003.

RÉSUMÉ: Les odes I, 4 et IV, 7 d' Horace ont des éléments comparables non seulement du point de vue du contenu mais aussi du point de vue formei malgré la différence de mètre et de ton. Dans ce bref article on examine ces similitudes et $l=$ on montre comment le grand poète portugais Camoëns a imité ces deux poèmes dans une mēme ode.

MOTS-CLÉS: Odes, Horace, Camoêns. 